\title{
High Resolution genotyping methods rule out urogenital Chlamydia trachomatis infection of an eight-year-old child recently resident in Afghanistan
}

Chloe Manning ${ }^{1}$, Helen Morris ${ }^{2}$, Joe Abbott' ${ }^{2}$, Mitul Patel' ${ }^{2}$, lan Clarke1, Peter Marsh ${ }^{1,3}$ University of Southampton, Faculty of Medicine ${ }^{1}$, Birmingham Children's Hospital NHS Foundation Trust ${ }^{2}$, Public Health England Laboratory, Southampton ${ }^{3}$

Chlamydia trachomatis (CT) is the leading cause of sexually transmitted infections worldwide, and $C$. trachomatis serovars A, B, Ba and C primarily infect ocular epithelial cells causing trachoma. Serovars A, B and Ba have been shown to cause urogenital infection in sporadic cases, whilst serovar $C$ has never before been associated with urogenital infection. Trachoma is the dominant infectious cause of blindness worldwide. Whilst rare in developed countries; trachoma is common in poverty-stricken regions including India, North Africa, and South East Asia. Symptoms of early stages of infection include conjunctivitis which can result in corneal opacity and blindness if untreated.

Aim: To determine the $C$. trachomatis ompA genotype of a $C$. trachomatis nucleic acid amplification test (NAAT) confirmed positive conjunctival swab from a child with established corneal inflammation who recently emigrated to the UK from Afghanistan. Neonatal conjunctivitis caused by vertical transmission of $C$. trachomatis from mother to neonate is rare in a child of this age, therefore sexual acquisition of $C$. trachomatis must be ruled out.

Objectives: (a) Extract and purify C. trachomatis DNA from the conjunctival swab; (b) ompA PCR the extracted DNA; (c) purify $P C R$ products; (d) ompA sequence analysis to determine $C$. trachomatis genotype.

\section{Materials and Methods}

Sample: A conjunctival swab was collected from an eightyear old child with established corneal inflammation who had recently migrated to the UK from Afghanistan. The swab tested positive for $C$. trachomatis using the RealTime $\mathrm{CT} / \mathrm{NG}$ assay (Abbott).

\begin{tabular}{|c|c|}
\hline $\begin{array}{l}\text { Extract } C \text {. } \\
\text { trachomatis DNA } \\
\text { from conjunctival } \\
\text { swab }\end{array}$ & $\begin{array}{l}\text { - NucleoSpin DNA Trace Tissue Kit } \\
\text { (Macherey-Nagel) } \\
\text { - Visualised on } 1 \% \text { agarose gel }\end{array}$ \\
\hline $\begin{array}{l}\text { ompA PCR } \\
\text { extracted DNA }\end{array}$ & $\begin{array}{l}\text { - Phusion High-Fidelity PCR using } \\
\text { PCTM3 and NRI primers } \\
\text { - Visualised on } 1 \% \text { agarose gel }\end{array}$ \\
\hline $\begin{array}{l}\text { Purify PCR } \\
\text { products }\end{array}$ & $\begin{array}{l}\text { - Wizard SV gel and PCR clean-up } \\
\text { system (Promega) } \\
\text { - Visualised on } 1 \% \text { agarose gel }\end{array}$ \\
\hline ompA sequence & $\begin{array}{l}\text { - Primers and purified DNA sent to } \\
\text { Source BioScience }\end{array}$ \\
\hline $\begin{array}{c}\text { ompA sequence } \\
\text { analysis }\end{array}$ & $\begin{array}{ll}\text { - } & \text { Nucleotide BLAST search } \\
\text { - } & \text { ExPASy translation of nucleotide } \\
\text { sequence } \\
\text { - } \\
\text { Protein BLAST of open reading } \\
\text { frame (ORF) }\end{array}$ \\
\hline
\end{tabular}

\section{Results}

Size/ bp

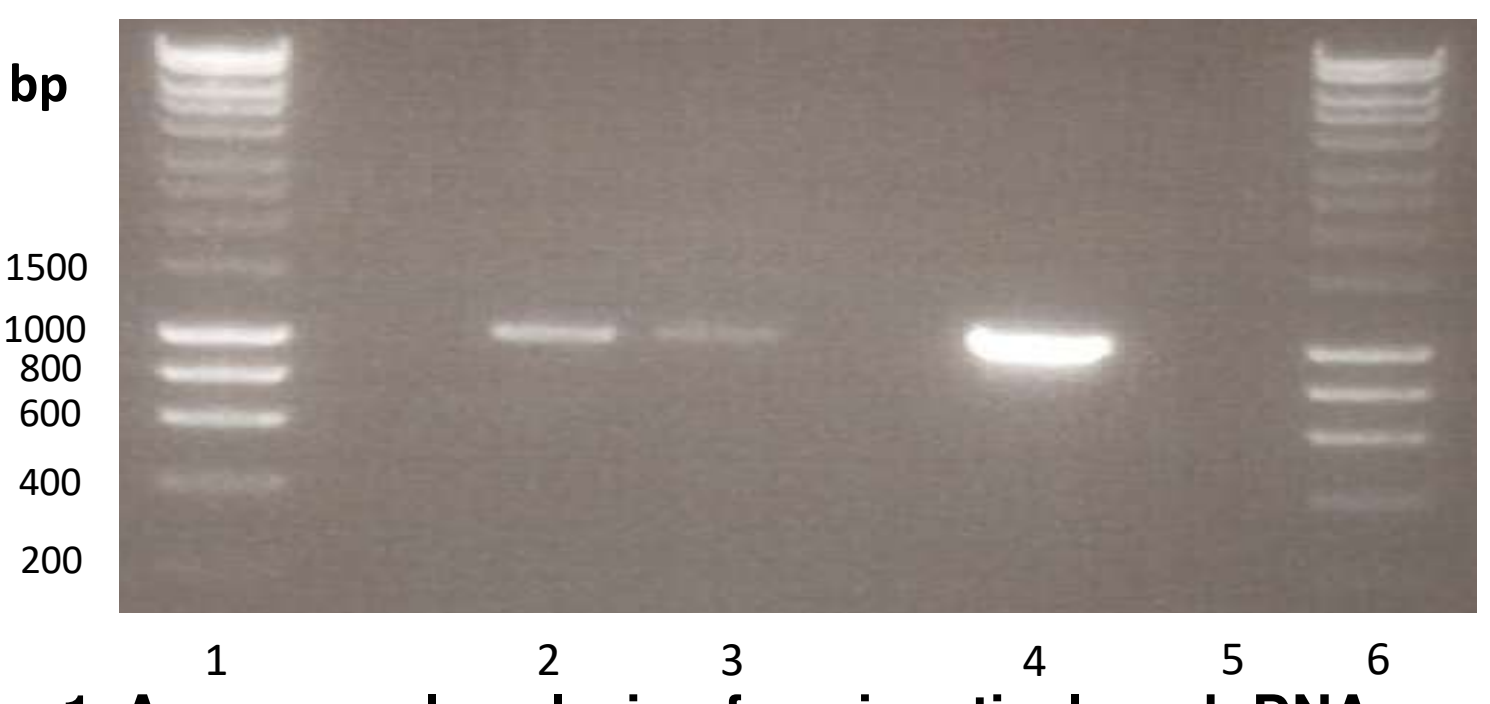

Figure 1. Agarose gel analysis of conjunctival swab DNA, and three reaction mixtures following ompA PCR amplification. [Lane 1=Hyperladder1 band size standard; Lane 2= conjunctival swab DNA; Lane 3= 1:8 dilution of sample; Lane $4=$ positive control (transformed $C$. trachomatis L2 P-pSW2GFP lab strain'); Lane 5= negative control; Lane $6=$ Hyperladder 1]

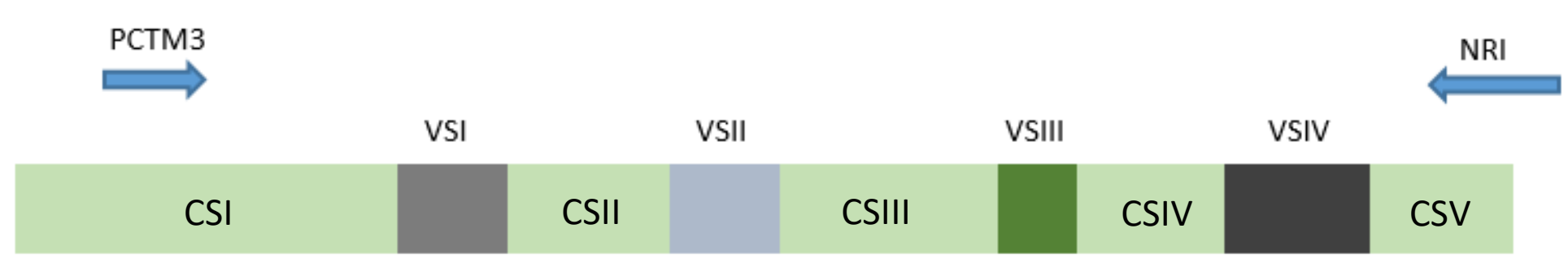

500

1000

(bp)

Figure 2. Schematic of ompA gene indicating the positions of variable sequences I-IV, and the target sites of the PCTM3 forward primer ${ }^{2}$ and the NRI reverse primer ${ }^{2}$ for ompA gene PCR amplification.

The ompA gene is comprised of four variable segments (VSI-IV) interspersed by five membrane-spanning conserved segments (CS). VS regions encode four variable protein domains that contain serovar-specific epitopes $^{3}$. Scale bar indicates number of nucleotide base pairs.

\section{Sample 235 YRLNMFTPYIGVKWSRVSFDADTIRIAQPKLAEAILDVTTLNPPTIAGRGNVVSGTDNEL 56 \\ Con. YRLNMFTPYIGVKWSRVSFDADTIRIAQPKLAEAILDVTTLNPTIAG+G+VVSSGTDNEL \\ Ref 275 YRLNMFTPYIGVKWSRVSFDADTIRIAQPRLAEAILDVTTLNPTIIAGKGSVVSSGTDNEL 334 \\ Sample 55 ADTMQIVSLQLNKMKSR \\ Con. ADTMQIVSLQLNKMKSR \\ Ref 335 ADTMQIVSLQLNKMKSR \\ NPTIAGRGNVVSSGT NPTIAG+G+VVSSGT NPTIAGKGSVVSSGT}

Figure 3. ompA-encoded amino acid sequence alignment of variable sequence IV (VSIV) from the patient sample to a reference conjunctival isolate belonging to ompA genotype $\mathrm{C}$, using the Basic Local Alignment Search Tool (BLAST).

[Row 1=patient sample; Row 2=consensus sequence showing location of amino acid changes between translated patient sample sequence and reference isolate; Row $\mathbf{3}=$ reference conjunctival isolate]. The sample showed the closest sequence homology (99\%) with this reference ompA genotype C conjunctival isolate.

\section{Conclusions}

The $C$. trachomatis DNA present in the sample shared the closest identity to ompA genotype $\mathbf{C}$, a known trachoma-causing ompA genotype that has never before been associated with urogenital infection

Ruled out sexual acquisition of $C$. trachomatis in the child

The strain was identical to known ompA genotype $C$ sequences except in 2 locations within variable sequence IV (VSIV) of the ompA gene

- Limited epidemiological information recorded for trachoma status in Afghanistan - this strain represents the first reported trachomacausing $C$. trachomatis strain to be ompA-sequenced from the region 